\title{
Renée Ventresque, Saint-John Perse dans sa bibliothèque
}

\section{Fabio Scotto}

\section{Q OpenEdition}

1 Journals

\section{Edizione digitale}

URL: http://journals.openedition.org/studifrancesi/9030

DOI: 10.4000/studifrancesi.9030

ISSN: 2421-5856

\section{Editore}

Rosenberg \& Sellier

\section{Edizione cartacea}

Data di pubblicazione: 1 octobre 2008

Paginazione: 489

ISSN: 0039-2944

\section{Notizia bibliografica digitale}

Fabio Scotto, «Renée Ventresque, Saint-John Perse dans sa bibliothèque», Studi Francesi [Online], 155

(LII | II) | 2008, online dal 30 novembre 2015, consultato il 16 janvier 2021. URL: http://

journals.openedition.org/studifrancesi/9030 ; DOI: https://doi.org/10.4000/studifrancesi.9030

Questo documento è stato generato automaticamente il 16 janvier 2021.

\section{(c) (i) (9)}

Studi Francesi è distribuita con Licenza Creative Commons Attribuzione - Non commerciale - Non opere derivate 4.0 Internazionale. 


\title{
Renée Ventresque, Saint-John Perse dans sa bibliothèque
}

\author{
Fabio Scotto
}

\section{NOTIZIA}

RENÉE VENTRESQUE, Saint-John Perse dans sa bibliothèque, Paris, Honoré Champion, 2007

(«Littérature de notre siècle», 31), pp. 291.

1 Renée Ventresque, specialista riconosciuta di Saint-John Perse (1887-1975), studia in questa dotta e documentata monografia l'evoluzione dell'opera e delle relazioni letterarie del poeta attingendo alle notazioni autografe a margine dei suoi libri, consultati alla Fondation Saint-John Perse di Aix-en-Provence, oltre che al carteggio epistolare inedito tra Alexis Léger e Philippe Berthelot.

Nella Prima Parte, «Les choix philosophiques et littéraires», articolata in quattro capitoli, l'A. tratteggia il profilo intellettuale di Saint-John Perse, caratterizzato dall'odio per il positivismo e per il cattolicesimo sociale, e da una predilezione per Léon Bloy, Emerson e il panteismo (pp. 28-29). La cosmogonia di Amers risulta antimaterialista, anti-marxista e anti-nichilista, ed è tesa alla «représentation du cosmos comme un être vivant» (p. 61), anche rinviando a un fitto repertorio magico (p. 64, nota 144) e mitologico-favolistico (p. 68). Di qui il rifiuto dell'orientamento esistenzialista e dell'engagement di tipo sartriano, ma anche la diffidenza nei confronti del gollismo. La Seconda Parte, «Du livre au texte», che consta di cinque capitoli, studia la cultura sincretistica del poeta e il suo rapporto con il linguaggio, con un ottimo confronto con la poetica claudeliana che ben evidenzia la tributarietà di Anabase dal modello di Tête d'Or; preziosa la riflessione sull'intertestualità dell'autore, che spazia, su materiali eterocliti, dalla filosofia alla geologia (Édouard Suess e Marcel Bertrand, cap. 4) e alle scienze naturali, fino all'ornitologia (cap. 5). La Terza Parte, «Quant au livre», di quattro capitoli, mostra in particolare la genesi e l'esperienza singolarissima della propria «Pléiade» dallo stesso autore curata dopo aver ricevuto il Premio Nobel nel 
1960, nelle sue implicazioni narcisistiche e auto-finzionali, in particolare per quanto attiene al rapporto con Morand, Carlier, Paulhan e Claudel (cap. 3), suo vero modello. Il cap. 4 mostra l'influenza profonda, pur se come nascosta, che esercitò l'opera di Thoreau sugli anni più fecondi della poesia di Perse, quelli dell'esilio americano (p. 252). Renée Ventresque conclude, nel solco di Meschonnic, sull'inattualità dell'unitarietà "celebrativa" della lirica di Saint-John Perse che parrebbe «aux antipodes des attentes de la poésie d'aujourd'hui» (p. 268), pur accostandola, nella sua ambizione rivolta all'«(Euvre totale», al «Gesamtkunstwerk» di Wagner e a Le Fou d'Elsa di Aragon (p. 269). Ben strutturata la Bibliographie (pp. 271-282), cui seguono puntuali Index (pp. 283-288). Sempre in tema, si segnala altresì l'uscita del prezioso volume di HENRIETTE LEVILLAIN, Saint-John de Perse. Une lecture de "Vents" (Paris, Gallimard, 2006, «Série Saint-John Perse», 18, pp. 261). Nel suo Avant-propos (pp. 7-30) Levillain ben ricostruisce la genesi e la ricezione della raccolta, vero momento di snodo poetico ed esistenziale del percorso del poeta. Il commento a piè di pagina del testo, sempre preceduto per ogni canto da una breve premessa introduttiva di taglio esplicativo e riassuntivo, privilegia la chiarificazione linguistico-filologica della complessa terminologia, anche finemente mostrando attenzione ermeneutica al repertorio retorico dell'imagerie mitopoietica di Perse. 